\title{
New Methods for Tobacco Dependence Treatment Research
}

\author{
Timothy B. Baker, Robin Mermelstein, Linda M. Collins, Megan E. Piper, Douglas E. \\ Jorenby, Stevens S. Smith, Bruce A. Christiansen, Tanya R. Schlam, Jessica W. Cook, and \\ Michael C. Fiore
}

\section{Abstract}

Despite advances in tobacco dependence treatment in the past two decades, progress has been inconsistent and slow. This paper reviews pervasive methodological issues that may contribute to the lack of timely progress in tobacco treatment science including: the lack of a dynamic model or framework of the cessation process, inefficient study designs, and the use of distal outcome measures that poorly index treatment effects. The authors then present a phase-based cessation framework that partitions the cessation process into four discrete phases based on current theories of cessation and empirical data. These phases include: 1) Motivation, 2) Precessation, 3) Cessation, and 4) Maintenance. Within this framework it is possible to identify phase-specific challenges that a smoker would encounter while quitting smoking, intervention components that would address these phase-specific challenges, mechanisms via which such interventions would exert their effects and optimal outcome measures linked to these phase-specific interventions. Investigation of phase-based interventions can be accelerated by using efficient study designs that would permit more timely development of an optimal smoking cessation treatment package.

At a Brookings Institute Conference, David Kessler, former FDA Commissioner, observed that the impressive progress made in AIDS research can be attributed, in part, to the development of "surrogate endpoints" such as HIV viral load that index treatment effects in randomized clinical trials far earlier than the obvious clinical endpoint of survival duration (1). Kessler advocated the development of such surrogates for other diseases such as cancer: measures that would index effects that are powerfully linked with ultimate outcomes, but that can be ascertained relatively quickly and cheaply relative to such outcomes.

As Kessler's observations suggest, standard operating procedures within a research field can profoundly influence progress, regardless of other factors such as innovative ideas, powerful theories, and level of financial support. The current paper identifies methods in the field of tobacco research that may be hobbling progress in discovering and validating effective interventions. It then recommends several complementary strategies that may improve the yield of tobacco dependence treatment research, some of which may be relevant to other areas of research as well.

Potential Conflicts of Interest: Timothy B. Baker, Robin Mermelstein, Megan E. Piper, Jessica W. Cook, Stevens S. Smith, and Tanya R. Schlam have no potential conflicts of interest to disclose. Douglas E. Jorenby has received research support from the National Institute on Drug Abuse, the National Cancer Institute, Pfizer, Inc., Sanofi-Synthelabo, and Nabi Biopharmaceuticals. He has received support for educational activities from the National Institute on Drug Abuse and the Veterans Administration, and consulting fees from Nabi Biopharmaceuticals. Stevens S. Smith has received research support from Elan Corporation, plc. Over the last three years, Michael C. Fiore served as an investigator on research studies at the University of Wisconsin that were funded by Nabi Biopharmaceuticals. 


\section{Current status}

Considerable progress has been made in tobacco treatment research. The recent Public Health Service (PHS) clinical practice guideline Treating Tobacco Use and Dependence: 2008 Update (2), as well as multiple Cochrane Reports $(3,4)$, offer ample evidence of this progress. For instance, the field has: identified multiple types of effective cessation medications, established a strong dose-response relation between counseling intensity and outcome, shown that treatment can be delivered via diverse routes (in-person, via telephone, tailored messages), and has shown that these treatments work in different populations of smokers.

Despite these findings, one could argue that progress has been disappointing. For instance, relatively few types of behavioral and counseling interventions have been validated experimentally. The 2008 PHS Guideline identified only two counseling interventions as earning at least moderately strong research support: skill training and intratreatment social support. These earned only a moderate strength of evidence ("B") rating, reflecting intrinsic limitations in the available evidence. In fact, comparison of the Clinical Practice Guidelines over the past 20 years $(1996$ - 2008) reveals little progress in identifying new, effective behavioral interventions. In sum, we know little about which counseling contents are most effective, and little progress has been made in this area over the past 20 years.

We also have little understanding of how to best package interventions to maximize their net effects: e.g., via additive or interactive effects. For instance, we do not know which types of psychosocial interventions work best together, and which work best with pharmacotherapies. While new types of cessation medications have been introduced, we know little about how to use these optimally and how they exert their effects. Therefore, despite the introduction of multiple new cessation medications over the past 20 years, these medications have had only a modest impact on population-wide tobacco use (5-7). Moreover, we know relatively little about the optimal timing of interventions. When should counseling or pharmacotherapy start, and end? Finally, relatively modest increases in absolute success rates of smoking cessation call into question our research progress. In general, cessation rates produced by treatments today seem little higher than those produced by treatments developed 20-30 years ago (cf. 2,8-10), although extremely intensive treatments have shown higher success rates (11). In sum, despite some areas of progress there is evidence that tobacco cessation research is in a "rut" $(10,12-15)$.

While there may be many reasons for the relatively slow progress in intervention development, we will discuss one primary impediment. We believe that the field of smoking cessation research has not adopted a conceptual framework that encourages the engineering and testing of optimal packages of cessation elements. That is, the field has lacked a framework that organizes information about the challenges, treatment opportunities, and outcomes (see 16) that are relevant to the dynamic process of smoking cessation. The lack of such a framework has discouraged researchers from building optimal interventions in which effective intervention components are delivered at strategically selected times.

The field is faced with other key obstacles to progress. For instance, the effort to develop optimal packages of cessation interventions requires the screening of multiple interventions with regards to both type and timing and these require highly efficient research methodologies. While randomized clinical trials (RCTs) can be effective in evaluating an individual intervention component, they are not efficient for examining the individual effects of multiple components or their interactions. It is clear that we need more efficient research methods that speed the testing and identification of effective smoking interventions, methods that complement a conceptual framework that encourages the synthesis of evidence 
across the dynamic process of smoking cessation. In addition, traditional RCTs performed under ideal (efficacy) conditions may translate poorly into real-world settings, and current strategies for bridging this translation "gap" in real-world effectiveness studies are costly and time consuming $(17,18)$.

In sum, the development of optimal packages of intervention components has been hampered by: 1) the lack of a dynamic framework of the cessation process and the resultant use of insensitive outcome assays, 2) testing only isolated intervention components, 3) inefficient experimental designs that constrain the number of hypotheses that can be addressed both within and across studies, and 4) a practice of conducting formative evaluations of interventions in contexts that are unrepresentative of conditions of their intended use. The current paper addresses the first of these obstacles to progress, while the companion paper (19) addresses the remaining obstacles. Together, these two papers offer a conceptual framework and efficient research strategies that might accelerate the rate of progress in smoking cessation research. Specifically, we argue that superior progress will occur if we adopt new research strategies in several different areas: 1) use more sensitive and theoretically relevant outcome measures, 2) use a framework that promotes the optimal identification, testing, and integration of intervention components, 3) use more efficient experimental designs, and 4) conduct formative evaluation of interventions in conditions of real-world use. While all of these suggestions individually have merit (20-22), in our view, their coordinated use has the potential to advance progress significantly in tobacco intervention research.

\section{Problems with Outcome Measures}

Most studies of smoking cessation treatments, and grant proposals, focus on the ability of treatments to increase long-term cessation rates (e.g., 6- or 12-month point-prevalence abstinence; some studies do report short-term outcomes as well: $(23,24)$. Some studies and grant proposals may also focus on an outcome measure that spans the post-quit period (i.e., continuous abstinence or survival). These measures have important clinical and public health value as they reflect net or residual treatment effects across meaningful time periods. While research suggests that most relapse starts within the first 2 weeks of a quit attempt $(25,26)$, research also suggests that a considerable amount of relapse occurs after the 1-year follow-up mark (perhaps about $10 \%$ of the remaining abstainers per year), suggesting that even longer-term follow-up may be optimal for forecasting the duration and health benefits of sustained abstinence (27); although cf. (28).

Although the prognostication of long-term abstinence is one purpose of outcome assessment, it is also vital to detect therapeutic effects. Therefore, assessments may be good for one purpose, but not another. Specifically, long-term outcome measures may be fairly insensitive to treatment effects. This may occur for at least two reasons. First, these measures are temporally distant from treatment exposure, which may permit treatment effects to dissipate prior to assessment. For instance, to the extent that counseling treatments depend upon ongoing provision of social support from treatment personnel (2), their effects would be expected to diminish once that support stops. That is, some treatment effects may, by their very nature, have steep decay gradients.

Second, it is clear that many events affect long-term success, not just treatment. It is also clear that the likelihood that such events will occur increases with time. A wealth of research shows that long-term outcomes are affected by events such as stressors (29-31), exposure to highly provocative smoking cues and smokers $(32-36)$, alcohol use $(37,38)$, and smoking opportunities $(39,40)$. These events may or may not be viewed as sources of error that obscure important treatment effects; it depends upon what the treatment is supposed to do 
and how it does it. For instance, if a goal of treatment is to inoculate the smoker to future episodic or severe stressors, or reduce the likelihood of such events, then it would certainly be appropriate to measure treatment success on the basis of ability to avoid or weather such challenges (although this specific treatment mechanism might be tested better with a treatment by stressor interaction term). In theory, skill training interventions might produce their effects via such routes. In addition, long-term outcomes would provide reasonable tests of maintenance or relapse prevention treatments. Thus, in some cases, long-term outcomes could be relevant to tests of specific treatment actions.

However, we believe that a single-minded focus on long-term outcomes thwarts one of the primary goals of cessation research - identifying and quantifying the magnitude of treatment effects - because, in many cases, long-term outcomes are more likely to obscure treatment effects than detect them. This is because: 1) some treatment elements are not intended to produce their primary effects via blunting or avoidance of environmental threats - especially ones that occur many months after treatment termination; 2) the occurrence and severity of environmental threats will be somewhat random and unrelated to treatment, thereby increasing error; and 3) a considerable body of research suggests that most treatment effects occur while treatment is being applied: e.g., most treatments do not result in a "hardened" quitter - one who is more likely to weather future threats. There is evidence that treatment effects are most evident early in the course of treatment, and steadily dissipate thereafter (41). In keeping with these arguments, prediction studies tend to show that treatment is a potent predictor of outcomes at early follow-up time points, but not later ones, where contextual and dispositional factors loom large (42)

One piece of evidence that has been used to argue for diminished treatment effects over time is the convergence of survival curves (indexing abstinence success) as the follow-up interval increases (e.g., (41)). Hughes and Callas (43) recently distinguished between additive and multiplicative effect sizes that can be derived from abstinence over the post-quit period. Additive effect sizes are those that reflect the absolute difference in abstinence rates between the control and the experimental group as a function of total size of each group (e.g., 60 vs. $40 \%$ abstinence rates out of the total groups treated). Multiplicative effect sizes are those that reflect the ratio of abstinence rates in the experimental vs. the control groups (e.g., an odds ratio). Hughes and Callas point out that plotted abstinence rates may converge as the follow-up interval lengthens, but that this does not mean that the multiplicative effect size diminishes. That is, the absolute difference between two groups may shrink, but their ratio may not, as the abstinence rate in the control group shrinks (e.g., as would happen if the experimental group achieved abstinence rates of $60 \% \& 20 \%$ at $1 \& 6$ months, while the control group achieved abstinence rates of $30 \% \& 10 \%)$.

Hughes and Callas (43) are certainly correct that converging abstinence curves do not necessarily reflect diminishing multiplicative effect sizes. However, we believe that both substantive considerations and evidence suggest that treatment effects do tend to diminish with time, even when multiplicative effect sizes are considered, and that long-term outcomes tend to be relatively insensitive indices of treatment effects. As noted earlier, there are many influences on lapse/relapse events that are likely independent of treatment (e.g., fortuitous exposures to major stressors), and that could inflate error in detecting treatment effects. Another source of error that tends to increase with time is loss of subject contact/ ascertainment. This leads to uncertainty regarding outcome, often for a significant number of individuals by late follow-up intervals. Further, there is little evidence that we have identified treatments that reduce the likelihood of relapse once the treatment is discontinued; in fact, there is considerable evidence, even using multiplicative indices, that lapses and relapses increase once an active treatment is discontinued and that treatment effects diminish thereafter (44). 
Research on outcome milestones (45) also suggests relatively larger effects on early vs. late outcomes. In recent research on five different cessation medication interventions (46), the results showed that the odds ratios (a multiplicative effect size index) were consistently and meaningfully greater for all medication interventions for achievement of initial abstinence than for achievement of point-prevalence abstinence at 6 months. Continuous, proximal measures are especially likely to be more sensitive than are distal, binary ones. It is important to note that we are not saying that treatments do not produce significant long-term effects, but such effects are largely residues of more robust early effects. ${ }^{1}$

Thus, long-term treatment effects typically reflect the residue of earlier effects that may have been eroded or obscured by fortuitous events. Certainly, these effects are germane to any intervention that is expressly designed to extend initial abstinence, but here the researcher might ensure that only initial abstainers are included in analyses (45). Also, if a major hypothesized mechanism of treatment is to inoculate the smoker to future threats, then it is certainly important to use threat-related lapsing/relapsing as an outcome. However, much evidence suggests that this is not, in fact, how or why cessation treatments work, meaning that long-term outcomes will not sensitively index those effects (of course, some treatments could, in theory, produce such effects and they are worth searching for). If occurrence of environmental threats is not affected by treatment receipt (e.g., your dog is equally likely to die, or your marriage fail, whether or not you receive intratreatment support), and active treatment does not blunt them, then such threats should damage longterm outcomes more for successful treatments than for unsuccessful treatments or control conditions (to the extent that the latter two produce lower initial cessation). This is simply a reflection of the fact that environmental threats can spur relapse only amongst abstainers, and there are more of the former amongst those who received an effective cessation treatment. In other words, long-term outcomes may actually penalize treatments to the extent that they boost initial cessation (especially with additive effect sizes).

It is important to recognize some of the problems engendered by the field's fixation on longterm abstinence as a primary index of treatment outcome. One problem is that the use of an insensitive outcome indicator means that cessation treatment studies are typically inefficient. In the experience of the authors, grant proposals that target cessation treatments tend to be rejected out of hand if they are not adequately powered to detect a reasonable treatment effect at 6- or 12-months postquit, even if such outcomes are not terribly relevant to theoretically based treatment hypotheses. This means that researchers use larger groups than are necessary, which, no doubt, decreases the number of studies and experimental conditions that can be run for a given amount of research support. In addition, the use of an insensitive index means that some effective treatments are rejected as ineffective because error masks their impact. Finally, a reflexive use of long-term cessation outcomes may discourage researchers from formulating more specific hypotheses about particular effects of treatment, and when such effects should occur. That is, a formulaic approach to treatment assessment may distract researchers from thinking deeply about specific change processes, which outcomes should be most reflective of such processes, and when the effects should be manifest. A lack of tailoring measures to the theoretically implicated goals of the treatment may produce insensitive treatment evaluations. What is the alternative to the use of a generic, long-term outcome?

\footnotetext{
${ }^{1}$ There is evidence that as abstinence continues there may be intrinsic processes that thwart lapsing or relapsing and that this results in a point at which relapse becomes relatively unlikely (28). Thus, it is possible that with very long interventions, treatment will take the majority of individuals past this point and result in very durable effect sizes (e.g., $(11,47)$ ).
} 


\section{Phase-based Framework for Smoking Cessation Research and Treatment}

Identifying appropriate outcome measures demands that investigators generate causal models of treatment; what is the treatment intended to do, when will it do it, and how and when will the effects be manifested? Because smokers face different challenges, goals, and opportunities over the course of cessation, it may be advisable to use such knowledge in the generation of a phase-based model of cessation treatment (similar to the transtheoretical model; $(48,49)$. Thus, we believe that an informed selection of outcomes demands that the outcome assess whether the treatment is providing the individual what s/he needs, when s/he needs it. Below we discuss how data and theory might be used to identify sensitive outcome measures that themselves can be used to identify effective treatments. The phase-based framework that we are proposing is designed to provide an integrative context that allows the investigator to see how and when different interventions should be applied, and their effects assessed, based upon an appraisal of the challenges and opportunities presented by each phase of the cessation process.

The proposed phase-based framework is intended to integrate existing research on smoking motivation and cessation to address four core questions that are critical to selecting and evaluating effective intervention components: 1) What are the challenges and intervention opportunities that occur across the smoking cessation attempt? 2) What interventions are likely to address those challenges successfully? 3) What measures will sensitively index the therapeutic benefits of treatment? And, 4) What measures will index mechanisms or mediators of treatment benefit? In other words, the intent of this model is to identify promising interventions and ways to measure their effects and mechanisms of action accurately.

Several overarching principles should be considered when addressing these four core questions. One derives from the phase-based nature of cessation. The model assumes the existence of different phases in the process of smoking cessation, with phases being defined on pragmatic and empiric bases, with the assumption that the challenges that smokers face, and the optimal interventions and measures, differ across the phases. The model does not assume that a particular challenge, intervention, or measure is relevant to only one phase of cessation; rather, it assumes that phase-based relevance is by degree. A second principle is the notion that the challenges that smokers face, and opportunities for intervention, should influence the treatments that are tried. The assumption is that these will change across the cessation attempt, and that treatments selected for evaluation should be appropriate for the phase-based challenges and opportunities. This means that the proximal effects of treatments should redress hypothesized challenges and mediate clinical benefit (e.g., increased abstinence rates). This underscores the third principle that guides the application of the framework: the evaluation of mediational relations will index the extent to which a treatment is performing consistent with framework-based hypotheses. In other words, such analyses will reveal whether a treatment's hypothesized mechanisms of action address the targeted phase-based challenges. Thus, the framework emphasizes the importance of using sensitive, theoretically appropriate outcome measures and conducting mediational research that tests whether an intervention is working as hypothesized. In sum, the framework should suggest what interventions to use, when to use them, and how to evaluate them.

The above framework clearly assumes the need for two primary types of outcome measures. Investigators must identify measures that allow them to select treatments or intervention components that produce clinically meaningful effects (i.e., treatment selection measures). In addition, investigators should include measures of treatment mechanisms (measures that index mediators of clinical benefit: treatment mechanism measures). In sum, to address the four core questions critical to selecting and evaluating effective intervention components, 
this framework suggests the following: 1) different cessation phases present specific challenges and opportunities; 2 ) treatments applied and evaluated should be ones whose mechanisms of action address the phase-appropriate challenges and take advantage of the phase-specific opportunities (treatments should be "phase tuned"), 3) measures of mechanism should determine whether the tested treatments produce significant effects consistent with hypothesized mechanisms of action and whether these effects translate into significant clinical benefit; and 4) selection measures should be used to index clinically meaningful benefit, and such measures should be the primary basis of treatment selection for further evaluation or implementation. It is important to note that both the measures of mechanism and treatment selection should be appropriate for the challenges and opportunities presented by the phase in which they are used. Since the mediational models will relate treatment condition with both mechanism and selection measures, experiments guided by a phase-based strategy will test both the interventions and theories upon which they are based.

Comprehensive tests of phase-based treatment hypotheses via mediational models will reveal whether: 1) a treatment affects a mechanism; 2) variance in the mechanism is related to a clinically meaningful outcome (i.e., the treatment selection measure); 3 ) the treatment affects a clinically meaningful outcome (i.e., again, the treatment selection measure); 4) the treatment's effect on the mechanism accounts for its effects on the clinically meaningful outcome; and 5) a clinically meaningful outcome is affected by hypothesized mechanisms that are not significantly influenced by treatment (i.e., analyses can identify the causes of relapse that are unaffected by the tested treatments). Such information can be used to guide the future development and tests of treatments.

Stage- or phase-based models of smoking are not new. For instance, the transtheoretical model (48-50) shares features with the Phase-Based Model. The transtheoretical model has generated valuable research on tobacco interventions. The transtheoretical model is a theory of behavior change; it attempts to identify particular processes that account for change across both different stages and across different types of behaviors or problems. The proposed phase-based framework that we are advocating is not a theory. Rather, it is a strategy for using data and theories to identify impediments to change, generate hypotheses about possible timely interventions, and organize tests of both theory and interventions. Therefore, the proposed framework is not a transtheoretical theory or model of behavior change, but rather it is a conceptual and methodologic strategy that can be used with any theories that seem appropriate. In addition, the goal of the framework is not intended to be relevant to all types of addictive disorders, but rather is intended specifically to be relevant to smoking cessation (although, this sort of approach could be modified for use with other types of disorders or behavior problems). Therefore, the framework is appropriate for smoking-specific risks or change processes (e.g., home or work smoking policies, withdrawal-induced anhedonia). In addition, it is not focused on synthetic factors or metavariables to account for change over time (e.g., the "processes of change" that were selected to be at a "mid-level of abstraction" in the transtheoretical model; (51). Rather, the framework is appropriate for variables at any level of analysis: e.g., conditioned responses, electrophysiological responses indicative of motivational processing, and self-report of attitudes. Such variables may reflect relevant change processes at only a single phase of the cessation process.

The phase-based framework can be used in conjunction with different and specific models of associative learning, motivational models of addiction, and neuropharmacologic evidence, and so on. Therefore, another difference between this framework and the transtheoretical model is that it does not reflect an attempt to measure or integrate change processes that are common to many different theories or models of change (cf. (51)). What 
we are recommending is a broad application of a phase-based framework (partly inspired by the transtheoretical model) that can be used to test a diverse range of hypotheses, theories, assessments, and interventions. While it comprises a framework similar to that of the transtheoretical model, it attempts to organize the application of theory, but does not constitute a theory.

In surveying changes in challenges, opportunities, and goals over the course of cessation, we suggest dividing the cessation process into four phases (see Figure 1). We label the first phase the Motivation Phase, which persists until the smoker is ready to make a quit attempt. The second phase, the Precessation Phase, is defined somewhat pragmatically as the period of several weeks prior to the actual quit attempt; i.e., this phase is relevant to the person who has made a commitment to a quit attempt. ${ }^{2}$ While this duration is admittedly somewhat arbitrary, the current definition is based on the length of prequit interventions that have demonstrated efficacy (2), and also on our clinical experience that suggests that the smoker will lose motivation if the preparatory intervention is too long. It is clear though, that the suggested phase lengths are somewhat arbitrary and should be servants to hypotheses and the data available, and not vice versa. The Cessation Phase is defined as the 2 weeks immediately following the quit attempt, when both withdrawal severity and the likelihood of initial lapses are highest. The Maintenance Phase is an open-ended period of time following the Cessation Phase when clinicians wish to apply and study treatments designed to extend or reinstate abstinence following a quit attempt. Clearly, those smokers who fail to quit become appropriate for a motivational or precessation treatment at some future point in time.

The phase-based framework as we propose it does not assume that phases are wholly distinct from one another. Rather, it assumes that phases differ by degree, with some processes and events being more relevant to some phases than others (e.g., while withdrawal peaks immediately post-cessation, individuals experience withdrawal before quitting and months afterwards; (55-57). The proposed framework acquires value to the extent that it organizes evidence and hypotheses about the challenges and opportunities that vary across the course of cessation and that these suggest different treatments and treatment goals (see discussion below).

There is ample evidence to support the view that challenges differ across times demarcated by the four proposed phases. For instance, before smokers quit smoking their withdrawal symptoms and craving are somewhat suppressed by their on-going smoking, and smokers differ from one another relatively little in terms of withdrawal severity (58). However, once smokers stop smoking, withdrawal and craving typically jump precipitously on the quit day and remain somewhat elevated over the first 1 - 2 weeks post-cessation (58-60). Thereafter, smokers show highly heterogeneous withdrawal patterns or trajectories with some showing steady decreases, others chronic elevations, and still others, highly volatile patterns (55-57). While severity of withdrawal and craving at diverse time points can predict cessation success (56), there is mounting evidence that the immediate jump in symptoms on the quit day is an especially potent determinant of such success $(58,61,62)$. Therefore, the evidence suggests that withdrawal and craving differ in severity, course, and relation with ultimate cessation success over the suggested phases. In theory, such information could be used to engineer treatments so that the timing and nature of interventions meets the nature of the phase-based challenges. A phase-based approach might also clarify which phases and

\footnotetext{
${ }^{2}$ Some smokers make quit attempts in an apparently spontaneous manner. They do not select a quit day nor formally state an intention to quit $(52,53,54)$. The current model is designed to organize and assess interventions and intervention evaluations. Obviously, there would be little opportunity to organize Precessation interventions for the person who makes an unplanned quit attempt, and the framework would not, by itself, indicate the motivational factors that resulted in such a quit attempt. A theory such as the transtheoretical model would be more appropriate for that purpose.
} 
challenges have been most refractory to treatment, and this might inform future research efforts. Therefore, while the phases are based on clear clinical demarcations (not willing to quit, willing to quit, occurrence of a quit attempt), their primary utility is their ability to organize data and hypotheses that are relevant to phase-specific interventions and assessment (e.g., see Table 1).

Not only do challenges differ over phases but clinical goals do as well. As Prochaska, DiClemente and others have noted, the majority of smokers are not ready to make a quit attempt at any given point in time (e.g., (63)), and so for many clinicians the chief goal is to motivate quit attempts. However, once the smoker has decided to try to quit, the question becomes one of how to prepare the smoker for cessation when s/he initially faces the need to attain abstinence, and then later, the goal becomes the maintenance or reestablishment of abstinence.

Some of the clinical implications of the phases are obvious; individuals who are not yet ready to make a quit attempt clearly need to be motivated to make one (e.g., (51)). A Precessation phase may be conceptualized as an opportunity to train motivated individuals who are not yet struggling with withdrawal-induced distress and frequent urges. The immediate Postcessation phase is a time where many individuals experience a dramatic increase in withdrawal - which presents an opportunity for treatments to suppress withdrawal symptoms, and so on. So, there is a fairly compelling reason to demarcate phases in the cessation process because they seem to have clear relevance for treatment. ${ }^{3}$

Below we provide a very brief synopsis of the challenges as well as the treatment and measurement opportunities present at the various cessation phases. This is offered to demonstrate how such a phase-based framework could be used to organize extant data, to complement various theoretical models, and to generate hypotheses about treatment effects. Of course, some caveats pertain: There is great variation amongst smokers in some of the events and processes discussed, one could find other bases for defining phases than the ones suggested, and some processes and events are highly relevant to multiple phases. Therefore, the following is presented as a tentative model of how the framework might be used, i.e., one that has heuristic value and that requires refinement and reformulation via additional research.

\section{Motivation}

The goals of this phase are to stimulate quit attempts and make them more successful. Some of the challenges are low motivation, lack of therapeutic support (as clinicians or others do not typically intervene with such smokers or provide cessation related support), high levels of nicotine dependence (heavy and automatic smoking, strong cue-smoking contingencies, smoking reinforcement), and often low expectations of success (e.g., lack of success in quitting, controlling urges/avoiding withdrawal; (2,26,64-70); see Table 1). The challenges suggest treatment opportunities designed to enhance quitting motivation via reduced nicotine dependence or smoking rate through use of medication (e.g., (71)) that suppresses smoking rates and blunts nicotine reinforcement (72-74) and through the use of behavioral intervention that reduces environmental contingencies with smoking $(75,76)$. Research on smokers who were unwilling to quit suggests positive effects of such interventions such as smoking reduction counseling (77), nicotine replacement therapy (NRT) use $(2,77,78)$, and motivational counseling interventions $(2,70,79)$, with data suggesting increases in either

\footnotetext{
${ }^{3}$ Other bases could have been used for the demarcation of phases. For instance, the Transtheoretical model defines stages based upon both pragmatic considerations, such as a person's willingness or attempt to quit, and upon patterns of change processes over time (51). We also emphasize a pragmatic strategy, one based on clinically useful distinctions, in order to promote more general buy-in by diverse investigators, which might lead to greater adoption of a common framework and complementary research efforts.
} 
subsequent quit attempts, cessation likelihood, or both. Such behavioral intervention can also provide smokers with easily accomplished successive approximations to abstinence that may enhance self-efficacy. It is clear that some of these treatments may produce multiple effects; use of nicotine medication may both reduce smoking rate and make it easier for a smoker to reduce smoking in key locations (80).

As noted above, the investigator should be interested in two major types of measures of treatment effectiveness: treatment selection measures and measures of mechanism (see Table 1). With regards to the former, motivational interventions should boost stated intention to quit, quit attempts, and, possibly, quitting success when an attempt is made. While an investigator might certainly relate a motivational intervention to long-term quitting success, as noted earlier, this might be an insensitive index of effectiveness. After all, if one truly adopts a phase-based approach, the job of the motivational intervention is not to promote maintenance of abstinence, rather it is to boost quit attempts and early quitting success. The use of long-term outcomes such as 6-month point-prevalence rates might be insensitive to treatment effects that are quite large when more temporally proximal and phase-appropriate measures are used (73). It is also possible that interventions delivered during the Motivational phase might affect only one of the selection outcomes. For instance, there is evidence that motivational interviewing and prequit smoking reductions increase quit attempts, but it is unclear that they increase the success of such attempts $(2,77)$. Other interventions, such as use of NRT by smokers who are unwilling to quit, appear to increase subsequent quitting success, and might increase both types of outcomes $(77,81)$.

In general, treatment selection measures should have clear clinical relevance, but may provide little information about specific mechanisms of change. Measures of mechanism should be targeted at variables that are sensitive to theoretically specified change processes. Formal tests of mediation $(82,83)$ could reveal the extent to which such measures are responsive to treatment and also account for change in the treatment selection measures. For instance, smoking reduction during Motivation might work via multiple mechanisms. It could reduce nicotine dependence, given the relation of dependence severity to nicotine intake (83), it could work by reducing the contingency between smoking and key environmental contexts, or it might work by giving smokers an opportunity to practice urge coping prior to the quit attempt (Table 1). Prequit NRT use might work via similar mechanisms. For instance, prequit NRT suppresses smoking $(80,81)$, and this may reduce dependence (80,84); although Rose et al. (73) report that the benefits of prequit NRT are greater amongst those low in dependence). Prequit NRT also may result in a reduced contingency between smoking and nicotine receipt, which might weaken context-nicotine associations, or the presence of NRT-derived nicotine in the body might blunt smoking reinforcement. Finally, prequit NRT reduces the smoker's craving or perceived need for tobacco (80); although (84), which might enhance his/her expectations of success or selfefficacy. These might, in turn, increase the likelihood that the smoker would make a quit attempt and succeed in it. Motivational counseling would presumably enhance individuals' intrinsic motivation to quit, their decisional balance, and perhaps their perceived selfefficacy as well. These represent just a select list of candidate mechanisms - other possibilities might include a change in incentive value or expectations of reinforcement. These potential mechanisms could be studied with ecological momentary assessment strategies (EMA), ambulatory transducers, or possibly laboratory measures.

This example illustrates the complementary nature of selection and mediation assays. While it would be theoretically important to determine if a motivational treatment actually increases self-efficacy or intrinsic motivation to quit, outcomes based on these measures would not constitute a sufficient basis for treatment selection. Conversely, selection measures don't provide much of a basis for treatment refinement or development, and 
provide relatively little grist for theory evaluation. Measures of mechanism, however, should reveal considerable information relevant to the latter goals. Therefore, use of the phasebased framework can help scientists identify the key measures needed to answer both key questions in cessation research - does it work and how does it work?

One additional point should be made. While there is evidence that each of several interventions (prequit NRT, prequit smoking reductions, motivational counseling) might be effective per se, we have virtually no information regarding such vital questions as: the relative effectiveness of these interventions, their additive effects, their interactive effects, their effects when used with different sorts of cessation interventions (effects which might also be orthogonal, overlapping or interactive), and so on. In other words, while we have some evidence regarding the effects of such treatments when they are added to a set, or uniform, treatment package, we do not know how such treatments could be used optimally with a range of other treatment elements. This can be attributed, at least in part, to a sole reliance on the RCT, which makes it nearly impossible to explore the independent and joint effects of multiple intervention components $(21,85)$. For instance many of the available studies tested combined intervention elements: e.g., prequit NRT use and smoking reduction counseling generally were used together in experimental analyses (see (77); although (80)) so that their separate, additive, or interactive effects cannot be gauged. Also, because these interventions were sometimes not evaluated as motivational interventions per se, their relevance to motivationally-important outcomes such as quit attempts have not been studied adequately. Instead, some studies focused on generic cessation outcomes such as continuous or point-prevalence abstinence. The relevance of efficient experimental designs to treatment evaluation using the phase-based framework is discussed further in the companion article (19).

\section{Precessation}

Smokers face several major challenges when they first quit. They face innumerable cues and contexts that have been highly associated with smoking and that trigger smoking urges via associative processes (86-88). They also experience rapid escalation in withdrawal symptoms including increases in negative affect and urges (e.g., $(58,59))$. Moreover, any lapsing during this early period is highly dangerous, being linked with high rates of ultimate relapse $(26,89)$. Further, smokers have typically not practiced coping with urges or withdrawal prior to the quit attempt. Thus, the Precessation Phase may be an ideal time to intervene - before the smoker is faced with the onslaught caused by initial cessation. During Precessation, withdrawal symptoms are relatively mild (58), there is extended opportunity for learning and practice, motivation to smoke has not spiked due to withdrawal, and a "failure" to execute the treatment plan properly (cope well) will not greatly imperil the quit attempt. These Precessation challenges and opportunities suggest that certain intervention components could increase subsequent cessation success. For instance, Precessation medication could, as in the Motivation Phase, blunt the pharmacologic and rewarding effects of smoking before cessation (i.e., explicit unpairing of smoking and reward which may affect smoking expectations), and suppress smoking rate (24,78,80,90-92).

In addition, Precessation counseling and behavioral training could target: 1) the acquisition of coping skills including proper medication use and learning about smoking triggers and challenges $(2,35,36,84,93,94) ; 2)$ increased motivation for participants with low motivation to quit via internalization of quitting motives and acquisition of greater self-efficacy $(70,79)$; 3 ) social support via an ongoing relationship with a counselor $(2,54)$; 4) extinction of smoking cues via massed exposure (e.g., via denicotinized cigarettes or while using a partial antagonist such as varenicline; (86,95-98); 5) reduced dependence and associative strength via practice quit attempts (50) and via decreased smoking (cutting down to 5-10 cigarettes/ 
day) for 2 weeks prior to the quit attempt (e.g., $(71,75,76,99))$; and 6$)$ reduced density of smoking cues through altering of life contexts and situations as well as new smoking policies (e.g., no smoking in the car). The last targets of counseling are suggested by evidence that smoking cues can powerfully elicit smoking urges and perhaps lapses, and that personal or societal smoking policies are associated with increased likelihood of successful cessation (86,97,100-102). Practice quit attempts may be useful since they may allow the smoker to adapt to early withdrawal symptoms and may allow her/him to practice coping in the context of abstinence distress (103).

As noted earlier, a comprehensive phase-based framework should guide the selection of phase-based outcomes in addition to the phase-appropriate treatments. The challenges and interventions discussed above would suggest the measurement of mechanisms or mediators such as self-efficacy, perceived intra-treatment support, practice/use of coping skills, and reduced prequit smoking (see Table 1). In addition, reduced dependence, craving, and withdrawal during the prequit and immediate post-quit period could constitute useful measures of mechanism. In terms of treatment selection measures, amount of smoking in the immediate postquit period could constitute a phase-relevant measure of how well the Precessation interventions prepare the smoker for the challenges of the post-quit period. One such useful measure might be ability to quit on the quit day (45). Another useful and sensitive measure might be number of days abstinent in the first two weeks of the quit attempt.

Data from our previous research allowed us to test multiple candidate measures that might reflect sensitively the effects of Precessation and Cessation intervention components. After examining many indicators, including 7-day point-prevalence abstinence at 1 or 2 weeks postquit and days to first cigarette, we identified total number of days abstinent in the first two weeks after the quit attempt (i.e., during the Cessation Phase) as a useful early cessation treatment selection measure. Using data from multiple prior clinical trials we determined that this measure was sensitive to a variety of treatment effects, and that it was strongly related to long-term cessation outcomes. Moreover, this outcome is quasi-continuous which has better measurement properties than does a binary measure (16). Using data from one of our large clinical trials (104), we found that this measure was strongly related to receiving active pharmacotherapy $(t(606)=-5.8, p<.001)$ and to 6-month abstinence status (Wald = $62.1, p<.001$; logistic regression analysis controlling for nicotine dependence [using the Fagerstrom Test of Nicotine Dependence] and treatment). These results were replicated using the 1504 participants from a study comparing five different pharmacotherapy conditions (105). This study showed a fairly linear relation between number of days abstinent at the 2-week post-quit mark and abstinence at 6 months; on average, participants who were abstinent at 6-months were abstinent on 12 days or more regardless of intervention group (placebo or active medication conditions). In contrast, participants who were smoking at 6 months were, on average, abstinent on only six days. These results are quite consistent across the multiple samples in our prior work and show that this measure reflects intervention effects and predicts long-term outcome. Previous research supports the validity of early smoking as an accurate index of eventual cessation outcome $(26,89,106)$ and agrees with the suggestion by Perkins, Stitzer and Lerman (107) that short-term smoking effects may be a useful basis for initial evaluation of intervention components. This measure (i.e., total number of abstinent days at 2-weeks postquit; range $=0$-14) is not offered as the optimal measure of the effectiveness of Precessation or Cessation interventions. Rather, it is offered as an example of the sort of measure, and its properties, that might constitute a more sensitive index of treatment effects during these phases, but one that also has strong implications for ultimate success. Data from this same study (105) show that ability to establish initial abstinence ( $24 \mathrm{hr}$ of nonsmoking) was highly sensitive to 
treatment effects and yielded larger effect sizes than did later outcome assays (e.g., 6-month point prevalence; (46)).

As with the interventions suggested for the Motivation Phase, in general, the proposed interventions for the Precessation Phase have never been evaluated on the basis of their joint and interactive effects.

\section{Cessation Phase}

The primary goal of Cessation Phase intervention components is complete abstinence early in the quit attempt. While there are no doubt multiple challenges that occur during this phase, data suggest that the rapid escalation in withdrawal symptoms, especially craving, is a key factor in precipitating slips or lapses back to smoking early in the post-quit period $(58,83)$. There is also a decline in positive affect, which also has been linked with cessation failure (83). In addition, situational or contextual dangers (seeing others smoking, experiencing stressors, drinking alcohol) increase the likelihood that a person will lapse or relapse $(89,108,109)$. Finally, initial smoking lapses are more likely in the first 2 weeks of the quit attempt than at any other time, and such lapses are highly likely to transition into full relapse (e.g., $(26,89))$. The data on number of days smoking just reviewed suggest that there is a linear relation between number of days smoking and ultimate outcome, which suggests that it is vital to limit the amount of lapsing.

Ironically, while the vast majority of research attention has been paid to the evaluation of treatments administered during the immediate post-quit period, this period may be particularly inopportune for smokers to receive some types of treatments. For instance, treatments that require learning, extensive self-regulation, and so forth (e.g., skill training), may be undermined by the withdrawal distress and cognitive demands of relearning highly mapped behavioral patterns (110), which are characteristic of the early postquit period. Thus, treatment opportunities must be evaluated with regards to the time constraints and distress of this phase. Therefore, while considerable skill training may ideally occur during the Precessation phase, in the Cessation Phase smokers may benefit most from an intensive, supportive intervention that buffers them from temptation and stressors (2). In addition, combination pharmacotherapy should be especially beneficial during this phase since it has been shown to provide greater suppression of the withdrawal syndrome than monotherapy. Moreover, examination of smoking cessation milestones has shown that combination pharmacotherapy (nicotine patch + lozenge) is more effective at boosting initial cessation rates and delaying initial lapses than is monotherapy (46). Cessation pharmacotherapy treatment should: 1) blunt the rapid rise in withdrawal symptoms that occurs within the first 24 hours of quitting (58);2) reduce the overall level of withdrawal $(82,83)$; and 3$)$ enhance positive affect (83).

As indicated above, treatments may differ in nature and goal as a function of cessation phase. For instance, exposure to danger cues might be encouraged during the Precessation period (to promote extinction and coping practice) but avoided during Cessation when withdrawal has significantly elevated the incentive value of smoking cues $(111,112)$, when distress is at a peak, and when a slip may undermine the whole quit attempt. In addition, while skill training and practice of skills might be appropriate for the Precessation Phase, intensive support over the first several days of the quit attempt might be optimal in the Cessation Phase. Finally, while considerable research shows that combination pharmacotherapy is relatively efficacious during the Cessation Phase, such evidence does not exist for the Precessation Phase. The above analysis of challenges and opportunities suggests that initial cessation success (e.g., establishment of initial abstinence, days of abstinence in the first 2 weeks) would constitute meaningful and sensitive Cessation Phase 
outcomes. Meaningful mechanism measures might include withdrawal severity, perceived intra-treatment support, positive affect, and so on. Of course, treatment-mediator relations will differ as a function of treatment type: e.g., medication will exert its effects on initial cessation by suppressing urges and by enhancing positive affect $(61,62)$.

Although there has been considerable research on the suggested Cessation intervention components, there has been little research that identifies optimal combinations of these components alone or when they are used with optimal Precessation and/or Maintenance intervention components and evaluated with diverse criteria (e.g., cost-effectiveness, exposure). Thus, we do not know which components exert complementary, overlapping, or interactive effects.

\section{Maintenance Phase}

The goal of this phase is the maintenance of abstinence, or a return to it following a lapse or relapse (of course, at some point the relapser may be uninterested in continuing the quit attempt and the Motivation or Precessation Phases may be viewed as more relevant.). Admittedly, its start date ( 2 weeks postquit) is somewhat arbitrary. However, some justification can be offered both for separating the Maintenance Phase from the Cessation Phase, and for the former's start date. One reason for separating the Maintenance Phase from the Cessation Phase is to highlight that while numerous treatments have been shown to aid cessation, effective Maintenance treatments have been harder to identify. There is evidence that sustained counseling support or information $(11,113)$ may be effective maintenance interventions, however. These approaches certainly suggest promising approaches to maintenance. In addition, there is little evidence of how best to restart a quit attempt. Therefore, this Phase can be distinguished from the Cessation Phase by a relative dearth of efficacious types of intervention; it represents a knotty clinical research challenge that is worth denoting. Setting the start of the Maintenance Phase at 2-weeks postquit is consistent with the fact that for most smokers withdrawal symptoms are declining by this point (59). Therefore, challenges other than the initial, abstinence-instigated surge in withdrawal are implicated in lapses and relapses in the Maintenance Phase.

The smoker who has been abstinent or largely abstinent for 2 weeks is faced with some of the same challenges as the more recent quitter: e.g., cravings. However, additional challenges associated with relapse are especially relevant during this phase, including: 1) exacerbations of withdrawal that may occur weeks after the quit day when a smoker is unprepared for them $(55,57) ; 2)$ an escalation in smoking causing a smoker to progress from a lapse to a full relapse (45); 3 ) a decrease in self-efficacy due to anhedonia or prolonged withdrawal $(41,114-117) ; 4)$ the premature termination of either medication or counseling (e.g., (44,118-120), and 5) poor medication adherence (93). The exacerbations in withdrawal and craving that occur in some individuals appear to be due, at least in part, to encounters with environmental smoking triggers (58). With regards to adherence, research consistently shows that smokers take far less medication than is recommended, especially during the Maintenance Phase, and that low rates of medication use are associated with cessation failure $(93,121)$.

These challenges offer Maintenance-specific treatment opportunities. Counseling and behavioral intervention can produce: 1) increased motivation via intra-treatment support and competence enhancement interventions $(11,70,113) ; 2)$ renewed quit attempts amongst those who have begun to lapse/relapse (122); and 3) increased pleasurable activities to reduce pleasure deficits or anhedonia (123); 4) prolonged access to treatment support (11); and 5) lifestyle modification to reduce exposure to smoking opportunities and cues (113). Research on adherence to medications for other disorders suggests that behavioral interventions, such 
as patient education and electronic monitoring and feedback systems (e.g., (124-126)), may boost adherence markedly. Prolonged use of NRT or other medications during the Maintenance Phase may: 1) reduce progression of lapses to full relapse (e.g.,(45,46)); 2) reduce the likelihood or severity of prolonged or labile withdrawal (120); and 3) reduce anhedonia associated with withdrawal $(24,83,90)$. While there is some evidence supporting the case for prolonged medication use (44,127-129), the data are mixed (2). Therefore, as with the other cessation phases, extant data certainly suggest candidate interventions that could be effective in the Maintenance Phase. However, at present, as with the other phases, we know little about the relative efficacies of these interventions, whether they produce complementary effects, and so on.

In keeping with the above analysis of Maintenance Phase challenges and treatment opportunities, treatment selection criteria might include the ability of treatments to delay and/or prevent lapses and relapse during the Maintenance Phase. In addition, long-term point-prevalence could also be used since this would detect the effects of requitting. Measures of mechanism might target medication adherence, perceived support, anhedonia, withdrawal lability, exposure to smoking triggers, and so on (see Table 1).

\section{A Phase-Based Framework: Synthesis}

A phase-based framework fosters a synthesis of knowledge about the time-course and nature of cessation challenges with knowledge about intervention effects. Ultimately, this should permit the generation of a comprehensive intervention package that is "phase-tuned" to produce optimal, relevant effects at each phase of cessation (where both the type and timing of treatment are optimized). Such phase-tuning is based upon the assumption that the benefits of exposure to optimal treatments will accumulate over the different phases of cessation; i.e., that long-term abstinence in a population of smokers will be fostered by treatments that induce a high proportion of smokers to make quit attempts, attain high levels of initial abstinence or greatly reduced smoking, and maintain durable abstinence or reduced lapse-relapse transition after the quit attempt. That is, a Motivational or Precessation treatment might not, by itself, significantly boost abstinence rates at distant follow-up time points, but the additive (or possibly interactive) effects of optimal treatments in each phase may produce optimal net clinical benefit. The model also assumes that the identification of optimal interventions requires the use of sensitive, phase-based assessments of both treatment selection and treatment mechanisms. Such assessments should, of course, be validated in multiple ways via construct validation methods. Although effective interventions may not be identified at each cessation phase, an advantage of a phase-based strategy assures that no period in the cessation process is ignored or overlooked.

The value of a phase-based approach should be seen in the rate of research progress that attends its adoption. For instance, hypotheses should focus on the particular challenges and opportunities that arise during a targeted cessation phase, the potential additive and interactive effects of treatments should be addressed - both within and across phases, clear hypotheses should be advanced and tested regarding treatment mechanisms, and outcome measures should be highly appropriate and sensitive to treatment effects. Not only should hypotheses about treatments, and assessments of treatments, be more comprehensive and focused, but superior treatments should be generated and tested because of a more planful approach to selecting and testing treatments that are appropriate to phase-based opportunities and challenges. All of this should yield greater progress in smoking cessation treatment research and higher quit rates from smoking cessation interventions.

While our review of the four proposed phases reveals some of the promise and advantages of a phase-based strategy, it also exposes the scope of the evaluative problem that confronts 
us. Ideally, the unique and complementary effects of interventions must be evaluated with regards to other interventions within the same phase as well as across the four phases. With multiple and different interventions to be tested at each of the four phases, the number of potential experimental and statistical comparisons is daunting. Clearly, what is needed is a strategy that allows large scale, programmatic, and efficient evaluation of multiple intervention components, selection of the most promising, and then systematic tests of synthesized composite interventions (i.e., packages of intervention components). Thus, we need methods to assemble intervention components so the package of components yields optimal, net effects. Moreover, interventions may stack-up differently against one another depending on the particular outcome considered: e.g., initial abstinence, long-term pointprevalence abstinence, cost-effectiveness, and so on. This challenge is addressed in the companion article, "The Multiphase Optimization Strategy for Engineering Effective Tobacco Use Interventions," (19).

\section{Acknowledgments}

Funding: This research was supported by a grant 9P50CA143188-11 from the National Cancer Institute. Dr. Baker was supported via NCI 1K05CA139871. Dr. Piper was supported by grant 1UL1RR025011 from the Clinical and Translational Science Award (CTSA) program of the National Center for Research Resources (NCRR), National Institutes of Health (NIH). Dr. Cook was supported by K08DA021311.

\section{References}

1. Thornton M. The next front on the war on cancer. Wall Street Journal. 2009:Sect. A17.

2. Fiore, MC.; Jaen, CR.; Baker, TB., et al. Treating tobacco use and dependence: 2008 update. Rockville, MD: U.S. Department of Health and Human Services, U.S. Public Health Service; 2008.

3. Lancaster T, Stead LF. Individual behavioural counselling for smoking cessation. Cochrane Database Syst Rev. 2005; (2):CD001292. [PubMed: 15846616]

4. Stead L, Perera R, Lancaster T. Telephone counselling for smoking cessation. Cochrane Database of Syst Rev. 2006; (3):CD002850. [PubMed: 16855992]

5. Biener L, Reimer RL, Wakefield M, Szczypka G, Rigotti NA, Connolly G. Impact of smoking cessation aids and mass media among recent quitters. Am J Prev Med. 2006; 30(3):217-24. [PubMed: 16476637]

6. Cokkinides VE, Ward E, Jemal A, Thun MJ. Under-use of smoking-cessation treatments: results from the National Health Interview Survey, 2000. Am J Prev Med. 2005; 28(1):119-22. [PubMed: 15626567]

7. Solberg LI, Asche SE, Boyle R, McCarty MC, Thoele MJ. Smoking and cessation behaviors among young adults of various educational backgrounds. Am J Public Health. 2007; 97(8):1421-6. [PubMed: 17600256]

8. Fiore, MC.; Bailey, WC.; Cohen, SJ. Smoking cessation: Clinical practice guideline No 18. Rockville, MD: U.S. Department of Health and Human Services, Public Health Service, Agency for Health Care Policy and Research; 1996.

9. Fiore, MC.; Bailey, WC.; Cohen, SJ. Treating tobacco use and dependence: Clinical Practice Guideline. Rockville, MD: U.S. Department of Health and Human Services, U.S. Public Health Service; 2000.

10. Shiffman S. Smoking cessation treatment: any progress? J Consult Clin Psychol. 1993; 61(5):71822. [PubMed: 8245269]

11. Hall SM, Humfleet GL, Reus VI, Munoz RF, Cullen J. Extended nortriptyline and psychological treatment for cigarette smoking. Am J Psychiatry. 2004; 161(11):2100-7. [PubMed: 15514412]

12. Carroll KM. Relapse prevention as a psychosocial treatment: A review of controlled clinical trials. Exp Clin Psychopharmacol. 1996; 4(1):46-54.

13. Lichtenstein E, Hollis J. Patient referral to a smoking cessation program: Who follows through? J Fam Pract. 1992; 34(6):739-44. [PubMed: 1593248] 
14. Niaura R, Abrams DB. Smoking cessation: progress, priorities, and prospectus. J Consult Clin Psychol. 2002; 70(3):494-509. [PubMed: 12090365]

15. Piasecki TM, Baker TB. Any further progress in smoking cessation treatment? Nicotine Tob Res. 2001; 3(4):311-23. [PubMed: 11694198]

16. Velicer WF, Rossi JS, Diclemente CC, Prochaska JO. A criterion measurement model for health behavior change. Addict Behav. 1996; 21(5):555-84. [PubMed: 8876758]

17. Friend K, Levy DT. Smoking treatment interventions and policies to promote their use: A critical review. Nicotine Tob Res. 2001; 3(4):299-310. [PubMed: 11694197]

18. Hollis JF, Bills R, Whitlock E, Stevens VJ, Mullooly J, Lichtenstein E. Implementing tobacco interventions in the real world of managed care. Tob Control. 2000; 9(Suppl 1):I18-124. [PubMed: 10688926]

19. Collins LM, Baker TB, Mermelstein RJ, et al. The Multiphase Optimization Strategy for engineering effective tobacco use interventions. Ann Behav Med. 2011

20. Strecher VJ, McClure J, Alexander G, et al. Web-based smoking cessation components and tailoring depth: Results of a randomized trial. Am J Prev Med. 2008; 34:373-81. [PubMed: 18407003]

21. Collins LM, Murphy SA, Nair VN, Strecher VJ. A strategy for optimizing and evaluating behavioral interventions. Ann Behav Med. 2005; 30(1):65-73. [PubMed: 16097907]

22. Glasgow RE, Lichtenstein E, Marcus AC. Why don't we see more translation of health promotion research to practice? Rethinking the efficacy-to-effectiveness transition. Am J Public Health. 2003; 93(8):1261-7. [PubMed: 12893608]

23. Gonzales D, Rennard SI, Nides M, et al. Varenicline, an alpha4beta2 nicotinic acetylcholine receptor partial agonist, vs sustained-release bupropion and placebo for smoking cessation: a randomized controlled trial. JAMA. 2006; 296:47-55. [PubMed: 16820546]

24. Jorenby DE, Hays JT, Rigotti NA, et al. Efficacy of varenicline, an alpha4beta2 nicotinic acetylcholine receptor partial agonist, vs placebo or sustained-release bupropion for smoking cessation: a randomized controlled trial. JAMA. 2006; 296(1):56-63. [PubMed: 16820547]

25. Hughes JR, Keely J, Naud S. Shape of the relapse curve and long-term abstinence among untreated smokers. Addiction. 2004; 99(1):29-38. [PubMed: 14678060]

26. Kenford SL, Fiore MC, Jorenby DE, Smith SS, Wetter D, Baker TB. Predicting smoking cessation. Who will quit with and without the nicotine patch. JAMA. 1994; 271(8):589-94. [PubMed: 8301790]

27. Hughes JR, Peters EN, Naud S. Relapse to smoking after 1 year of abstinence: a meta-analysis. Addict Behav. 2008; 33(12):1516-20. [PubMed: 18706769]

28. Kirshenbaum AP, Olsen DM, Bickel WK. A quantitative review of the ubiquitous relapse curve. J Subst Abuse Treat. 2009; 36(1):8-17. [PubMed: 18571890]

29. Carey MP, Snel DL, Carey KB, Richards CS. Self-initiated smoking cessation: A review of the empirical literature from a stress and coping perspective. Cogn Ther Res. 1989; 13:323-41.

30. Carey MP, Kalra DL, Carey KB, Halperin S, Richards CS. Stress and unaided smoking cessation: a prospective investigation. J Consult Clin Psychol. 1993; 61(5):831-8. [PubMed: 8245280]

31. Weaver K, Campbell R, Mermelstein R, Wakschlag L. Pregnancy smoking in context: the influence of multiple levels of stress. Nicotine Tob Res. 2008; 10(6):1065-73. [PubMed: 18584470]

32. Derby CA, Lasater TM, Vass K, Gonzalez S, Carleton RA. Characteristics of smokers who attempt to quit and of those who recently succeeded. Am J Prev Med. 1994; 10(6):327-34. [PubMed: 7880551]

33. Homish GG, Leonard KE. Spousal influence on smoking behaviors in a US community sample of newly married couples. Soc Sci Med. 2005; 61(12):2557-67. [PubMed: 15978712]

34. Mermelstein R, Cohen S, Lichtenstein E, Baer JS, Kamarck T. Social support and smoking cessation and maintenance. J Consult Clin Psychol. 1986; 54(4):447-53. [PubMed: 3745596]

35. Shiffman S. Coping with temptations to smoke. J Consult Clin Psychol. 1984; 52(2):261-7. [PubMed: 6715652] 
36. Shiffman, S. Maintence and relapse: Coping with temptation. In: Nirenberg, TD., editor. Advances in the treatment of addictive behaviors. Norwood, NJ: Ablex; 1987. p. 353-85.

37. Dollar KM, Homish GG, Kozlowski LT, Leonard KE. Spousal and alcohol-related predictors of smoking cessation: a longitudinal study in a community sample of married couples. Am J Public Health. 2009; 99(2):231-3. [PubMed: 19059846]

38. Krall EA, Garvey AJ, Garcia RI. Smoking relapse after 2 years of abstinence: Findings from the VA Normative Aging Study. Nicotine Tob Res. 2002; 4:95-100. [PubMed: 11906685]

39. Bolt DM, Piper ME, McCarthy DE, et al. The Wisconsin Predicting Patients' Relapse questionnaire. Nicotine Tob Res. 2009; 11(5):481-92. [PubMed: 19372573]

40. Lee CW, Kahende J. Factors associated with successful smoking cessation in the United States, 2000. Am J Public Health. 2007; 97(8):1503-9. [PubMed: 17600268]

41. Piasecki TM, Fiore MC, McCarthy DE, Baker TB. Have we lost our way? The need for dynamic formulations of smoking relapse proneness. Addiction. 2002; 97(9):1093-108. [PubMed: 12199822]

42. Loh WY, Piper ME, Schlam TR, et al. Which patients will succeed and fail with smoking cessation pharmacotherapies? Towards a treatment assignment algorithm. Subst Use Misuse. in press.

43. Hughes JR, Callas PW. Errors in interpreting abstinence curves in studies of smoking cessation. Nicotine Tob Res. 2006; 8(1):7-12. [PubMed: 16497595]

44. Medioni J, Berlin I, Mallet A. Increased risk of relapse after stopping nicotine replacement therapies: a mathematical modelling approach. Addiction. 2005; 100(2):247-54. [PubMed: 15679754]

45. Shiffman S, Scharf DM, Shadel WG, et al. Analyzing milestones in smoking cessation: Illustration in a nicotine patch trial in adult smokers. J Consult Clin Psychol. 2006; 74(2):276-85. [PubMed: 16649872]

46. Japuntich SJ, Piper ME, Leventhal AM, Bolt DM, Baker TB. The effect of five smoking cessation pharmacotherapies on smoking cessation milestones. J Consult Clin Psychol. in press.

47. Hall SM, Humfleet GL, Munoz RF, Reus VI, Robbins JA, Prochaska JJ. Extended treatment of older cigarette smokers. Addiction. 2009; 104(6):1043-52. [PubMed: 19392908]

48. Prochaska JO, DiClemente CC. Stages and processes of self-change of smoking: toward an integrative model of change. J Consult Clin Psychol. 1983; 51(3):390-5. [PubMed: 6863699]

49. Prochaska, JO.; DiClemente, CC. Stages of change in the modification of problem behaviors. Newbury Park, CA: Sage; 1992.

50. Prochaska JO, Velicer WF. The transtheoretical model of health behavior change. Am J Health Promot. 1997; 12(1):38-48. [PubMed: 10170434]

51. Prochaska JO, Wright JA, Velicer WF. Evaluating theories of health behavior change: A hierarchy of criteria applied to the Transtheoretical Model. Appl Psychol. 2008; 57(4):561-88.

52. Nielsen A, Hannibal CG, Lindekilde BE, et al. Maternal smoking predicts the risk of spontaneous abortion. Acta Obstet Gynecol Scand. 2006; 85(9):1057-65. [PubMed: 16929410]

53. Ockene J, Ma Y, Zapka J, Pbert L, Valentine Goins K, Stoddard A. Spontaneous cessation of smoking and alcohol use among low-income pregnant women. Am J Prev Med. 2002; 23(3):1509. [PubMed: 12350446]

54. Bauld L, Chesterman J, Ferguson J, Judge K. A comparison of the effectiveness of group-based and pharmacy-led smoking cessation treatment in Glasgow. Addiction. 2009; 104(2):308-16. [PubMed: 19149828]

55. Piasecki TM, Fiore MC, Baker TB. Profiles in discouragement: Two studies of variability in the time course of smoking withdrawal symptoms. J Abnorm Psychol. 1998; 107(2):238-51. [PubMed: 9604553]

56. Piasecki TM, Niaura R, Shadel WG, et al. Smoking withdrawal dynamics in unaided quitters. J Abnorm Psychol. 2000; 109(1):74-86. [PubMed: 10740938]

57. Piasecki TM, Jorenby DE, Smith SS, Fiore MC, Baker TB. Smoking withdrawal dynamics: I. Abstinence distress in lapsers and abstainers. J Abnorm Psychol. 2003; 112(1):3-13. [PubMed: 12653409] 
58. McCarthy DE, Piasecki TM, Fiore MC, Baker TB. Life before and after quitting smoking: an electronic diary study. J Abnorm Psychol. 2006; 115(3):454-66. [PubMed: 16866586]

59. Hughes JR. Effects of abstinence from tobacco: etiology, animal models, epidemiology, and significance: a subjective review. Nicotine Tob Res. 2007; 9(3):329-39. [PubMed: 17365765]

60. Welsch SK, Smith SS, Wetter DW, Jorenby DE, Fiore MC, Baker TB. Development and validation of the Wisconsin Smoking Withdrawal Scale. Exp Clin Psychopharmacol. 1999; 7(4):354-61. [PubMed: 10609970]

61. McCarthy DE, Piasecki TM, Lawrence DL, Jorenby DE, Shiffman S, Baker TB. Psychological mediators of bupropion sustained-release treatment for smoking cessation. Addiction. 2008; 103(9):1521-33. [PubMed: 18783504]

62. Piper, ME.; Federman, EB.; McCarthy, DE., et al. Mediators of bupropion treatment effects. 14th Annual Meeting for the Society for Research in Nicotine and Tobacco; 2008 Feb 27-Mar 1; Portland, OR. 2008.

63. Etter JF, Perneger TV, Ronchi A. Distributions of smokers by stage: international comparison and association with smoking prevalence. Prev Med. 1997; 26(4):580-5. [PubMed: 9245682]

64. Baker TB, Piper ME, McCarthy DE, Majeskie MR, Fiore MC. Addiction motivation reformulated: An affective processing model of negative reinforcement. Psychol Rev. 2004; 111(1):33-51. [PubMed: 14756584]

65. Curry S, Wagner EH, Grothaus LC. Intrinsic and extrinsic motivation for smoking cessation. J Consult Clin Psychol. 1990; 58(3):310-6. [PubMed: 2195084]

66. Curry SJ, McBride C, Grothaus L, Lando H, Pirie P. Motivation for smoking cessation among pregnant women. Psychol Addict Behav. 2001; 15(2):126-32. [PubMed: 11419228]

67. Hatsukami, D.; Baker, TB. How tobacco causes disease: The biology and behavioral bases for tobacco-attributable disease: Report of the Surgeon General. U. S. Government Priority Office; Washington D.C.: Nicotine addiction: Past and present. in press

68. McBride CM, Curry SJ, Stephens RS, Wells EA, Roffman RA, Hawkins JD. Intrinsic and extrinsic motivation for change in cigarette smokers, marijuana smokers, and cocaine users. Psychol Addict Behav. 1994; 8:243-50.

69. Williams GC, Gagne M, Ryan RM, Deci EL. Facilitating autonomous motivation for smoking cessation. Health Psychol. 2002; 21(1):40-50. [PubMed: 11846344]

70. Williams GC, McGregor HA, Sharp D, et al. Testing a self-determination theory intervention for motivating tobacco cessation: supporting autonomy and competence in a clinical trial. Health Psychol. 2006; 25(1):91-101. [PubMed: 16448302]

71. Hughes JR, Carpenter MJ. Does smoking reduction increase future cessation and decrease disease risk? A qualitative review. Nicotine Tob Res. 2006; 8(6):739-49. [PubMed: 17132521]

72. Rose JE, Herskovic JE, Trilling Y, Jarvik ME. Transdermal nicotine reduces cigarette craving and nicotine preference. Clin Pharmacol Ther. 1985; 38(4):450-6. [PubMed: 4042528]

73. Rose JE. New findings on nicotine addiction and treatment. Nebr Symp Motiv. 2009; 55:131-41. [PubMed: 19013942]

74. LeSage MG, Keyler DE, Shoeman D, Raphael D, Collins G, Pentel PR. Continuous nicotine infusion reduces nicotine self-administration in rats with $23-\mathrm{h} /$ day access to nicotine. Pharmacol Biochem Behav. 2002; 72(1-2):279-89. [PubMed: 11900798]

75. Cinciripini PM, Lapitsky L, Seay S, Wallfisch A, Kitchens K, Van Vunakis H. The effects of smoking schedules on cessation outcome: can we improve on common methods of gradual and abrupt nicotine withdrawal? J Consult Clin Psychol. 1995; 63(3):388-99. [PubMed: 7608351]

76. Cinciripini PM, Wetter DW, McClure JB. Scheduled reduced smoking: effects on smoking abstinence and potential mechanisms of action. Addict Behav. 1997; 22(6):759-67. [PubMed: 9426793]

77. Hughes JR, Carpenter MJ. The feasibility of smoking reduction: an update. Addiction. 2005; 100(8):1074-89. [PubMed: 16042638]

78. Stead LF, Lancaster T. Interventions to reduce harm from continued tobacco use. Cochrane Database Syst Rev. 2007; (3):CD005231. [PubMed: 17636791]

79. Williams G, Minicucci D, Kouides R, et al. Self-determination, smoking, diet and health. Health Educ Res. 2002; 17(5):512-21. [PubMed: 12408196] 
80. Rose JE, Behm FM, Westman EC, Kukovich P. Precessation treatment with nicotine skin patch facilitates smoking cessation. Nicotine Tob Res. 2006; 8(1):89-101. [PubMed: 16497603]

81. Etter JF, Laszlo E, Zellweger JP, Perrot C, Perneger TV. Nicotine replacement to reduce cigarette consumption in smokers who are unwilling to quit: a randomized trial. J Clin Psychopharmacol. 2002; 22(5):487-95. [PubMed: 12352272]

82. McCarthy, DE.; Bolt, DM.; Baker, TB. The importance of how: A call for mechanistic research in tobacco dependence treatment studies. In: Treat, T.; Bootzin, RI.; Baker, TB., editors.

Psychological clinical science: recent advances in theory and practicer Integrative perspectives in honor of Richard M McFall. New York: Lawrence Erlbaum Associates; 2007. p. 133-63.

83. Piper ME, Federmen EB, McCarthy DE, et al. Using mediational models to explore the nature of tobacco motivation and tobacco treatment effects. J Abnorm Psychol. 2008; 117(1):94-105. [PubMed: 18266488]

84. Schuurmans MM, Diacon AH, van Biljon X, Bolliger CT. Effect of pre-treatment with nicotine patch on withdrawal symptoms and abstinence rates in smokers subsequently quitting with the nicotine patch: a randomized controlled trial. Addiction. 2004; 99(5):634-40. [PubMed: 15078238]

85. Collins LM, Murphy SA, Strecher V. The Multiphase Optimization Strategy (MOST) and the Sequential Multiple Assignment Randomized Trial (SMART): New methods for more potent eHealth interventions. Am J Prev Med. 2007; 32(5 Suppl):S112-8. [PubMed: 17466815]

86. Abrams DB, Monti PM, Carey KB, Pinto RP, Jacobus SI. Reactivity to smoking cues and relapse: Two studies of discriminant validity. Behav Res Ther. 1988; 26(3):225-33. [PubMed: 3408457]

87. Ferguson SG, Shiffman S. The relevance and treatment of cue-induced cravings in tobacco dependence. J Subst Abuse Treat. 2009; 36(3):235-43. [PubMed: 18715743]

88. Shiffman S, Gwaltney CJ, Balabanis MH, et al. Immediate antecedents of cigarette smoking: an analysis from ecological momentary assessment. J Abnorm Psychol. 2002; 111(4):531-45. [PubMed: 12428767]

89. Garvey AJ, Bliss RE, Hitchcock JL, Heinold JW, Rosner B. Predictors of smoking relapse among self-quitters: A report from the Normative Aging Study. Addict Behav. 1992; 17(4):367-77. [PubMed: 1502970]

90. Ferguson SG, Shiffman S, Gwaltney CJ. Does reducing withdrawal severity mediate nicotine patch efficacy? A randomized clinical trial. J Consult Clin Psychol. 2006; 74(6):1153-61. [PubMed: 17154744]

91. Rose, JE.; Uhl, GR. Disrupting nicotine reinforcement: From cigarette to brain. In: Uhl, GR., editor. Addiction reviews 2008 Annals of the New York Academy of Sciences. Malden: Blackwell Publishing; 2008. p. 233-56.

92. Bullen C, Whittaker R, Walker N, Wallace-Bell M. Pre-quitting nicotine replacement therapy: Findings from a pilot study. Tobacco Induced Diseases. 2006; 3(2):35-40. [PubMed: 19570295]

93. Lam TH, Abdullah AS, Chan SS, Hedley AJ. Adherence to nicotine replacement therapy versus quitting smoking among Chinese smokers: a preliminary investigation. Psychopharmacology (Berl). 2005; 177(4):400-8. [PubMed: 15289997]

94. Waldroup, WM.; Gifford, EV.; Kalra, P. Adherence to smoking cessation treatments. In: O'Donohue, WT.; Eric, R., editors. Promoting treatment adherence: A practical handbook for health care providers. Thousand Oaks, CA: Sage Publications, Inc.; 2006. p. 235-52.

95. Donny EC, Houtsmuller E, Stitzer ML. Smoking in the absence of nicotine: behavioral, subjective and physiological effects over 11 days. Addiction. 2007; 102(2):324-34. [PubMed: 17222288]

96. Donny EC, Jones M. Prolonged exposure to denicotinized cigarettes with or without transdermal nicotine. Drug Alcohol Depend. 2009; 104(1-2):23-33. [PubMed: 19446968]

97. Droungas A, Ehrman RN, Childress AR, O'Brien CP. Effect of smoking cues and cigarette availability on craving and smoking behavior. Addict Behav. 1995; 20(5):657-73. [PubMed: 8712062]

98. Rose, JE.; George, TP. Nicotine replacement therapies and other nicotinic strategies. In: George, TP., editor. Medication treatments for nicotine dependence. Boca Raton, FL: CRC Press; 2007. p. 63-74. 
99. Farkas AJ. When does cigarette fading increase the likelihood of future cessation? Ann Behav Med. 1999; 21(1):71-6. [PubMed: 18425657]

100. Juliano LM, Brandon TH. Reactivity to instructed smoking availability and environmental cues: evidence with urge and reaction time. Exp Clin Psychopharmacol. 1998; 6(1):45-53. [PubMed: 9526145]

101. Levy DT, Romano E, Mumford E. The relationship of smoking cessation to sociodemographic characteristics, smoking intensity, and tobacco control policies. Nicotine Tob Res. 2005; 7(3): 387-96. [PubMed: 16085506]

102. Nides MA, Rakos RF, Gonzales D, Murray RP, Tashkin DP, Bjornson-Benson WM. Predictors of initial smoking cessation and relapse through the first 2 years of the Lung Health Study. J Consult Clin Psychol. 1995; 63(1):60-9. [PubMed: 7896992]

103. McCarthy, DE.; Gloria, R.; Piper, ME.; Baker, TB. A pilot study to test the feasibility of precessation withdrawal exposure and rapid puffing among adult smokers motivated to quit. 15th Annual Meeting of the Society for Research on Nicotine \& Tobacco; 2009 Apr; Dublin, Ireland. 2009.

104. Piper ME, Federman EB, McCarthy DE, et al. Efficacy of bupropion alone and in combination with nicotine gum. Nicotine Tob Res. 2007; 9(9):947-54. [PubMed: 17763111]

105. Piper ME, Smith SS, Schlam TR, et al. A randomized placebo-controlled clinical trial of 5 smoking cessation pharmacotherapies. Arch Gen Psychiatry. 2009; 66(11):1253-62. [PubMed: 19884613]

106. Westman EC, Behm FM, Simel DL, Rose JE. Smoking behavior on the first day of a quit attempt predicts long-term abstinence. Arch Intern Med. 1997; 157(3):335-40. [PubMed: 9040302]

107. Perkins KA, Stitzer M, Lerman C. Medication screening for smoking cessation: a proposal for new methodologies. Psychopharmacology (Berl). 2006; 184(3-4):628-36. [PubMed: 16163529]

108. Brandon TH, Tiffany ST, Obremski KM, Baker TB. Postcessation cigarette use: The process of relapse. Addict Behav. 1990; 15(2):105-14. [PubMed: 2343783]

109. Shiffman S, Balbanis M. Do drinking and smoking go together? Alcohol Health Res World. 1996; 20(2):107-10.

110. Curtin, JJ.; McCarthy, DE.; Piper, ME.; Baker, TB. Implicit and explicit drug motivational processes: A model of boundary conditions. In: Weirs, RW.; Stacy, AW., editors. Handbook of implicit cognition and addiction. Thousand Oaks, CA: Sage; 2006. p. 233-50.

111. Gloria R, Angelos L, Schaefer HS, et al. An fMRI investigation of the impact of withdrawal on regional brain activity during nicotine anticipation. Psychophysiology. 2009; 46:681-93. [PubMed: 19490513]

112. Zinser MC, Fiore MC, Davidson RJ, Baker TB. Manipulating smoking motivation: Impact on an electrophysiological index of approach motivation. J Abnorm Psychol. 1999; 108(2):240-54. [PubMed: 10369034]

113. Brandon TH, Meade CD, Herzog TA, Chirikos TN, Webb MS, Cantor AB. Efficacy and costeffectiveness of a minimal intervention to prevent smoking relapse: dismantling the effects of amount of content versus contact. J Consult Clin Psychol. 2004; 72(5):797-808. [PubMed: 15482038]

114. Shiffman S, Paty JA, Gwaltney CJ, Dang Q. Immediate antecedents of unrestricted smoking patterns. J Abnorm Psychol. 2004; 113(1):166-71. [PubMed: 14992670]

115. Chaudhri N, Caggiula AR, Donny EC, Palmatier MI, Liu X, Sved AF. Complex interactions between nicotine and nonpharmacological stimuli reveal multiple roles for nicotine in reinforcement. Psychopharmacology (Berl). 2006; 184(3-4):353-66. [PubMed: 16240165]

116. Kenny PJ, Markou A. Conditioned nicotine withdrawal profoundly decreases the activity of brain reward systems. J Neurosci. 2005; 25(26):6208-12. [PubMed: 15987950]

117. Gwaltney CJ, Shiffman S, Balabanis MH, Paty JA. Dynamic self-efficacy and outcome expectancies: prediction of smoking lapse and relapse. J Abnorm Psychol. 2005; 114(4):661-75. [PubMed: 16351387]

118. Brandon TH, Zelman DC, Baker TB. Effects of maintenance sessions on smoking relapse: Delaying the inevitable? J Consult Clin Psychol. 1987; 55(5):780-2. [PubMed: 3454792] 
119. Helgason AR, Tomson T, Lund KE, Galanti R, Ahnve S, Gilljam H. Factors related to abstinence in a telephone helpline for smoking cessation. Eur J Public Health. 2004; 14(3):306-10. [PubMed: 15369039]

120. Tonstad S, Tonnesen P, Hajek P, Williams KE, Billing CB, Reeves KR. Effect of maintenance therapy with varenicline on smoking cessation: a randomized controlled trial. JAMA. 2006; 296(1):64-71. [PubMed: 16820548]

121. Schmitz JM, Sayre SL, Stotts AL, Rothfleisch J, Mooney ME. Medication compliance during a smoking cessation clinical trial: a brief intervention using MEMS feedback. J Behav Med. 2005; 28(2):139-47. [PubMed: 15957569]

122. Lando HA, Valanis BG, Lichtenstein E, et al. Promoting smoking abstinence in pregnant and postpartum patients: a comparison of 2 approaches. Am J Manag Care. 2001; 7(7):685-93. [PubMed: 11464427]

123. Hall SM, Munoz RF, Reus VI. Cognitive-behavioral intervention increases abstinence rates for depressive-history smokers. J Consult Clin Psychol. 1994; 62(1):141-6. [PubMed: 8034816]

124. Haynes RB, Yao X, Degani A, Kripalani S, Garg A, McDonald HP. Interventions to enhance medication adherence. Cochrane Database Syst Rev. 2005; (4):CD000011. [PubMed: 16235271]

125. Grabowski J, O'Brien CP, Greenstein R, Ternes J, Long M, Steinberg-Donato S. Effects of contingent payment on compliance with a naltrexone regimen. Am J Drug Alcohol Abuse. 1979; 6(3):355-65. [PubMed: 539577]

126. Elixhauser A, Eisen SA, Romeis JC, Homan SM. The effects of monitoring and feedback on compliance. Med Care. 1990; 28(10):882-93. [PubMed: 2232919]

127. Covey LS, Glassman AH, Jiang H, et al. A randomized trial of bupropion and/or nicotine gum as maintenance treatment for preventing smoking relapse. Addiction. 2007; 102(8):1292-302. [PubMed: 17624979]

128. Hays JT, Hurt RD, Rigotti NA, et al. Sustained-release bupropion for pharmacologic relapse prevention after smoking cessation. A randomized, controlled trial. Ann Intern Med. 2001; 135(6):423-33. [PubMed: 11560455]

129. Horst WD, Klein MW, Williams D, Werder SF. Extended use of nicotine replacement therapy to maintain smoking cessation in persons with schizophrenia. Neuropsychiatric Dis Treat. 2005; 1(4):349-55. 


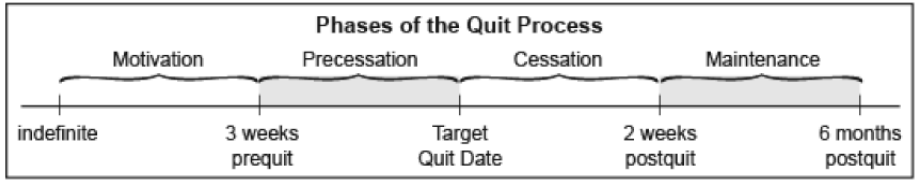

Figure 1. Longitudinal Phase-Based Model of Cessation 
Table 1

Exemplar Challenges, Intervention Components, Mechanisms and Treatment Selection Measures for the Suggested Four Smoking Cessation Phases

\begin{tabular}{|c|c|c|c|c|c|c|c|c|}
\hline \multirow{2}{*}{$\begin{array}{l}\text { Phase } \\
\text { Motivation }\end{array}$} & \multicolumn{2}{|c|}{ Exemplar Challenges } & \multicolumn{2}{|c|}{ Exemplar Intervention Components } & \multicolumn{2}{|c|}{$\begin{array}{l}\text { Exemplar Measures of } \\
\text { Mechanism }\end{array}$} & \multicolumn{2}{|c|}{$\begin{array}{l}\text { Exemplary Treatmen } \\
\text { Selection Measures }\end{array}$} \\
\hline & $\begin{array}{l}1 \\
2 \\
3 \\
4\end{array}$ & $\begin{array}{l}\text { Low } \\
\text { motivation } \\
\begin{array}{l}\text { High } \\
\text { dependence }\end{array} \\
\begin{array}{l}\text { Low self- } \\
\text { efficacy }\end{array} \\
\text { Lack of } \\
\text { support }\end{array}$ & $\begin{array}{l}\mathbf{1} \\
\mathbf{2} \\
\mathbf{3}\end{array}$ & $\begin{array}{l}\text { Prequit Medication } \\
\text { Behavioral intervention to } \\
\text { reduce smoking/ } \\
\text { contingencies } \\
\text { Motivational counseling }\end{array}$ & $\begin{array}{r}4 \\
5\end{array}$ & $\begin{array}{l}\text { Craving/ } \\
\text { withdrawal } \\
\text { Nicotine } \\
\text { dependence } \\
\text { Smoking rate } \\
\& \\
\text { contingencies } \\
\text { Self-efficacy } \\
\text { Intrinsic } \\
\text { motivation }\end{array}$ & 2 & $\begin{array}{l}\text { Stated } \\
\text { intention to } \\
\text { quit } \\
\text { Quit } \\
\text { attempts } \\
\text { Early } \\
\text { quitting } \\
\text { success }\end{array}$ \\
\hline Precessation & $\begin{array}{l}1 \\
2 \\
3\end{array}$ & $\begin{array}{l}\text { Smoking cues } \\
\& \text { contexts } \\
\text { Withdrawal \& } \\
\text { craving } \\
\text { Coping skill } \\
\text { practice }\end{array}$ & $\begin{array}{l}\mathbf{1} \\
\mathbf{2} \\
\mathbf{3}\end{array}$ & $\begin{array}{l}\text { Prequit medication } \\
\text { Behavioral intervention to } \\
\text { reduce smoking } \\
\text { contingencies, make } \\
\text { practice quit attempts, } \\
\text { practice coping, lifestyle } \\
\text { changes } \\
\text { Motivational \& supportive } \\
\text { counseling }\end{array}$ & 3 & $\begin{array}{l}\text { Perceived } \\
\text { support } \\
\text { Smoking rate } \\
\& \\
\text { contingencies } \\
\text { (cue } \\
\text { exposure) } \\
\text { Practice quit } \\
\text { attempts and } \\
\text { coping \& } \\
\text { symptomatic } \\
\text { reactions }\end{array}$ & 1 & 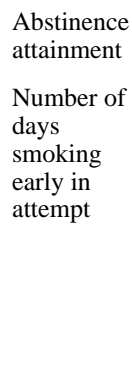 \\
\hline Cessation & $\begin{array}{l}1 \\
2 \\
2 \\
3 \\
4\end{array}$ & $\begin{array}{l}\text { Withdrawal \& } \\
\text { Craving } \\
\text { Decline in } \\
\text { positive affect } \\
\text { Smoking cues } \\
\text { Lapses }\end{array}$ & $\begin{array}{l}1 \\
2\end{array}$ & $\begin{array}{l}\text { Medication (intensive, } \\
\text { combination) } \\
\text { Supportive counseling }\end{array}$ & $\begin{array}{l}2 \\
3 \\
4\end{array}$ & $\begin{array}{l}\text { Withdrawal \& } \\
\text { Craving } \\
\text { increase \& } \\
\text { trajectory } \\
\text { Positive affect } \\
\text { Perceived } \\
\text { support } \\
\text { (buffered } \\
\text { temptations \& } \\
\text { stressors) } \\
\text { Self-efficacy }\end{array}$ & 2 & $\begin{array}{l}\text { Abstinence } \\
\text { attainment } \\
\text { Number of } \\
\text { days } \\
\text { smoking } \\
\text { early in } \\
\text { attempt }\end{array}$ \\
\hline Maintenance & $\begin{array}{l}1 \\
2 \\
3 \\
\\
4 \\
5\end{array}$ & $\begin{array}{l}\text { Lapses } \\
\text { Relapse } \\
\text { Resurgent } \\
\text { withdrawal \& } \\
\text { craving } \\
\text { Anhedonia } \\
\text { Declines in } \\
\text { Motivation } \\
\text { Stressors } \\
\text { Nonadherence }\end{array}$ & $\begin{array}{l}1 \\
2 \\
3 \\
4\end{array}$ & $\begin{array}{l}\text { Medication (extended) } \\
\text { Adherence interventions } \\
\text { Supportive counseling } \\
\text { Maintenance skill training } \\
\text { (coping, lifestyle change) }\end{array}$ & $\begin{array}{l}2 \\
3 \\
4\end{array}$ & $\begin{array}{l}\text { Medication } \\
\text { use } \\
\text { Withdrawal \& } \\
\text { Craving } \\
\text { (levels, } \\
\text { volatility) } \\
\text { Anhedonia } \\
\text { Intrinsic } \\
\text { motivation } \\
\text { Lapse } \\
\text { response (self- } \\
\text { efficacy, } \\
\text { motivation, } \\
\text { craving) } \\
\text { Perceived } \\
\text { support }\end{array}$ & 2 & $\begin{array}{l}\text { Lapses \& } \\
\text { lapse } \\
\text { latency } \\
\text { Relapse \& } \\
\text { relapse } \\
\text { latency } \\
\text { Number of } \\
\text { days } \\
\text { smoking } \\
\text { Point- } \\
\text { prevalence } \\
\text { abstinence }\end{array}$ \\
\hline
\end{tabular}




\begin{tabular}{|l|l|c|l|l|}
\hline Phase & Exemplar Challenges & Exemplar Intervention Components & $\begin{array}{l}\text { Exemplar Measures of } \\
\text { Mechanism }\end{array}$ & $\begin{array}{l}\text { Exemplary Treatment } \\
\text { Selection Measures }\end{array}$ \\
\hline & & & $7 \begin{array}{l}\text { Response to } \\
\text { smoking cues } \\
\text { (craving, } \\
\text { lapsing) }\end{array}$ & \\
& & & & \\
\hline
\end{tabular}

